\title{
PENGEMBANGAN PEMBELAJARAN AL-QUR'AN HADITS SURAH AZ-ZALZALAH PADA MEDIA E-LEARNING BERBASIS EDMODO
}

\author{
Ika Wahyu Nurdiana'), Abdulloh Hamid ${ }^{2)}$, Winarto Eka Wahyudi ${ }^{3)}$ \\ ${ }^{1,2)}$ UIN Sunan Ampel Surabaya \\ ${ }^{3)}$ Universitas Islam Lamongan \\ e-mail: ikanurdiana1310@gmail.com ${ }^{1)}$, doelhamid@uinsby.ac.id ${ }^{2)}$, \\ ekawahyudi@unisla.ac.id ${ }^{3)}$
}

\begin{abstract}
ABSTRAK
Berdasarkan kriteria pembelajaran al-Qur'an Hadits dengan materi surah az-Zalzalah dapat dikatakan valid dan efektif bagi peserta didik kelas IV Madrasah Ibtidaiyah. Untuk menyusun dan menghasilkan suatu pembelajaran maka diperlukan penelitian pengembangan media e-learning melalui edmodo. Dapat meningkatkan kreativitas peserta didik pada pembelajaran al-Qur'an Hadits tentang surah az-Zalzalah yang menggunakan media e-learning melalui edmodo. Jenis penelitian model ADDIE yang telah digunakan pada pengembangan pembelajaran al-Qur'an Hadits melalui media e-learning edmodo. Ada 5 tahapan dalam model ADDIE, yaitu analisis, perancangan, pengembangan, penerapan dan evaluasi. Telah divalidasi oleh 3 orang dosen sebagai ahli validator, media dan instrumen pada media e-learning melalui edmodo. Adapun subyek dalam penelitian pengembangan adalah peserta didik kelas IV tahun pelajaran 2020-2021 yang berjumlah 30 anak. Pembelajaran al-Qur'an Hadits surah az-Zalzalah dapat dikatakan baik dan memenuhi syarat dengan hasil rating 78,34\% melalui media e-learning edmodo. Akan tetapi, peserta didik dapat merespon media pembelajaran tersebut dengan hasil rating 82,36\% dan telah dinyatakan baik. Dengan demikian, keseluruhan aspek media elearning melalui edmodo pada pembelajaran al-Qur'an Hadits surah azZalzalah dapat dikategorikan baik dan layak untuk dapat digunakan dalam proses pembelajaran tersebut.
\end{abstract}

Kata kunci: Al-Qur'an Hadits, Media E-learning, Edmodo 


\section{ABSTRACT}

Based on the criteria of learning al-Qur'an Hadith with the material of surah az-Zalzalah, it can be said that it is valid and effective for grade IV students of Madrasah Ibtidaiyah. To compile and produce learning, it is necessary to research the development of e-learning media through edmodo. Can increase the creativity of students in learning al-Qur'an Hadith about surah azZalzalah using e-learning media through edmodo. This type of research is the ADDIE model that has been used in the development of Al-Qur'an Hadith learning through edmodo e-learning media. There are 5 stages in the ADDIE model, namely analysis, design, development, application and evaluation. Has been validated by 3 lecturers as validator experts, media and instruments on e-learning media through edmodo. The subjects in development research were 30 grade students for the 2020-2021 school year. Learning al-Qur'an Hadith surah az-Zalzalah can be said to be good and meet the requirements with a rating of $78.34 \%$ through the edmodo e-learning media. However, students can respond to the learning media with a rating of $82.36 \%$ and have been declared good. Thus, all aspects of e-learning media through edmodo in learning al-Qur'an Hadith surah az-Zalzalah can be categorized as good and feasible to be used in the learning process.

Keywords: Al-Qur'an Hadith, Media E-learning, Edmodo

\section{A. PENDAHULUAN}

Edmodo merupakan salah satu pembelajaran menggunakan platform sebagai media sosial yang diperuntukkan pendidik dan peserta didik dalam belajar serta mendapatkan suatu interaksi pembelajaran. Edmodo juga dapat mempromosikan jaringan pendidikan yang hampir sama dengan facebook. ${ }^{1}$ Akan tetapi, sifatnya lebih aman dan pribadi karena guru yang membuat serta mengelola akun tersebut. Dengan cara memberikan kode kepada peserta didik, agar bisa gabung dan dapat mengakses informasi atau penugasan pada aplikasi edmodo. Pendidik membantu peserta didik untuk menghubungkan dan mengkolaborasi waktu pembelajaran dengan tatap muka di luar. Edmodo digunakan $I C T$.

${ }^{1}$ Kongchan, C. (2008). How a non-digital Native Teacher Makes use of Edmodo. 
secara gratis dan aman dalam pembelajaran peserta didik di lingkungan pendidikan. Kemajuan komunikasi pada peserta didik sangat mendukung karena pendidik dapat menyampaikan beberapa informasi dan memberikan penilaian terhadap tugas peserta didik.

Dalam mengembangkan potensi individu dan masyarakat pada pendidikan perlu disadari oleh manusia sebagai tumpuan harapan. Dapat berjalan dengan baik jika pada pembelajaran terdapat proses interaksi bagi peserta didik dan sumber belajar di lingkungan belajar. ${ }^{2}$ Kebutuhan pada konsep dan mekanisme pembelajaran akan semakin meningkat dengan melalui perkembangan Information Technology (IT) yang semakin pesat. Kemajuan internet sekarang ini mempengaruhi setiap kegiatan organisasi bahkan dalam kehidupan sehari-hari masyarakat. Sebuah revolusi dibutuhkan untuk sistem pembelajaran dengan menggunakan media e-learning melalui edmodo yang telah mendapatkan dukungan ilmu pengetahuan dan teknologi.

Dengan memanfaatkan teknologi komputer maka jaringan internet dalam pendidikan dan pembelajaran jarak jauh dapat dikatakan sebagai e-learning. ${ }^{3}$ Peserta didik dapat berperan aktif dalam pembelajaran, membuat perancangan dan mencari materi yang diajarkan oleh seorang pendidik melalui usaha tiap individu agar bisa mengakomodasi suasana pembelajaran e-learning. Adapun istilah lain yang mengacu pada $e$ learning adalah online learning atau web based learning. Proses belajar mengajar secara online, bukan tatap muka disebut dengan konsep $e$ learning. Menggunakan media e-learning diharapkan dapat meningkatkan hasil belajar yang difungsikan sebagai tambahan, pelengkap dan pengganti oleh peserta didik. ${ }^{4}$ Dalam menerima serta mengolah informasi yang disajikan secara online, maka pembelajaran lebih ditekankan pada keakuratan dan ketelitian peserta didik.

Adanya media e-learning dapat memungkinkan para peserta didik untuk mempelajari melalui handphone, komputer atau laptop di tempat

\footnotetext{
${ }^{2}$ Rusman. (2014). Pendekatan, Strategi, dan Model Pembelajaran. PT Raja Grafindo.

${ }^{3}$ Smp, D. I., Depok, M., Dahlan, U. A., Dahlan, U. A., \& Dahlan, U. A. (2016). PENGEMBANGAN MEDIA E-LEARNING BERBASIS EDMODO PADA MATA PELAJARAN MATEMATIKA KELAS VII. 84-87.

${ }^{4}$ Samudra, U. (2018). Improving Character Education Strengthening Through. Setiawan 2013, 2262-2267.
} 
tinggal masing-masing tanpa harus mengikuti pembelajaran di dalam kelas. LMS (Learning Management System) merupakan salah satu jenis media e-learning yang dapat diterapkan di Madrasah. Yang lebih dikenal sebagai perangkat lunak dan dapat digunakan untuk mengelola kegiatan pembelajaran dan membuat materi secara online serta mencantumkan hasil-hasilnya tiap peserta didik. Semua kebutuhan dari para pengguna, ada pada fitur-fitur LMS yang juga memiliki keunggulan tersendiri. Salah satu media pembelajaran yang dapat digunakan setiap mata pelajaran dan tidak melalui aktivitas maupun pengamatan secara langsung dinamakan dengan edmodo.

Akan tetapi, fenomena yang terjadi di lapangan masih belum dikatakan optimal dalam memanfaatkan teknologi jejaring internet terutama e-learning. Karena masih beberapa sekolah yang sudah menggunakan e-learning berbasis edmodo. Padahal anak-anak zaman sekarang lebih tanggap dan pintar dalam mengaplikasikan gadget atau handphone. Adapun penyebab hal tersebut, yaitu kurangnya dukungan media e-learning yang dimanfaatkan oleh peserta didik dengan lebih maksimal, sebagian dari pendidik belum menguasai teknologi internet dan terkadang ada juga peserta didik yang mengeluh dengan jaringan internet yang kurang mendukung di daerahnya.

Pembelajaran yang kurang maksimal dalam mengakses $e$-learning, dapat menjadikan peserta didik kurang berminat dalam mengikuti pembelajaran online yang sedang berlangsung. Adapun kegiatan yang sudah terlaksana dalam pembelajaran ini adalah memberikan contoh video bahkan power point untuk menguatkan peserta didik pada materi yang telah disajikan. Dengan menggunakan media jaringan internet sebagai jenis belajar mengajar yang dapat tersampaikan materi pembelajaran kepada peserta didik diartikan sebagai e-learning. ${ }^{5}$

Dengan pemanfaatan menggunakan e-learning, maka pemecahan masalah dalam belajar materi al-Qur' an Hadits tentang surah az-Zalzalah dapat dijadikan sebuah alternatif. Karena pembelajaran al-Qur'an Hadits biasanya lebih kepada metode ceramah, penyampaian materi yang cenderung monoton dapat menjadikan bosan dan malas bagi peserta

\section{Press.}

${ }^{5}$ Munadi. (2008). Media Pembelajaran (Sebuah pendekatan baru). Gaung Persada 
didik sehingga ketercapaian tujuan pembelajaran tidak bisa diperoleh. Dengan cara memanfaatkan e-learning melalui edmodo, maka pelaksanaan pembelajaran secara online dapat dilakukan dan mampu memberikan informasi kepada kelompok yang lain. Berdasarkan pemaparan diatas, maka penelitian ini merangkai judul tentang "Pengembangan Pembelajaran Al-Qur'an Hadits Materi Surah AzZalzalah Pada Media E-learning Berbasis Edmodo".

\section{B. METODE PENELITIAN}

Dalam mengembangkan suatu media e-learning melalui edmodo pada pembelajaran al-Qur'an Hadits materi surah az-Zalzalah merupakan tujuan dari digunakannya metode penelitian Research and Development (R\&D), yang telah diujicobakan kepada peserta didik kelas IV secara terbatas dan juga menguji kelayakan dalam bentuk media. Adapun sasaran pada penelitian ini adalah perangkat pembelajaran yang pada media pembelajarannya berupa video dan power point berisikan materi pembelajaran tentang surah az-Zalzalah.

Pembelajaran al-Qur'an Hadits materi surah az-Zalzalah dengan menggunakan media e-learning melalui edmodo dapat dikembangkan dan diujicobakan secara terbatas pada suatu kelompok peserta didik yang merupakan rancangan dari jenis penelitian Research and Development ${ }^{6}$ Menguji suatu produk dibutuhkan enam tahapan yang diakhiri dengan tahap analisa data merupakan bagian terpenting dalam sebuah penelitian. Akan tetapi, penelitian ini dapat dikatakan efektif dan layak produk data dengan menggunakan keempat tahapan selanjutnya pada ruang lingkup yang lebih luas untuk mendapatkan hasil yang lebih maksimal.

Ahli validator memberikan lembar validasi pada instrument penelitian suatu perangkat pembelajaran al-Qur'an Hadits. Para ahli validator terdiri dari 3 dosen, yaitu 1 dosen pengampu dari Universitas Islam Negeri Surabaya, 1 dosen dari Institut Agama Islam Negeri Samarinda dan 1 dosen dari Universitas Islam Lamongan. Model

${ }^{6}$ Pendidikan, S., Elektro, T., Surabaya, U. N., Elektro, T., Teknik, F., \& Surabaya, U. N. (2009). PENGEMBANGAN MEDIA PEMBELAJARAN E-LEARNING MENGGUNAKAN EDMODO PADA MATA PELAJARAN ELEKTRONIKA DASAR STUDI PADA SISWA KELAS X TEI SMK NEGERI 2 BOJONEGORO Wisda Putra Atmanegara Puput Wanarti Rusimamto Abstrak. 
pengembangan yang mempunyai orientasi kelas pada prosedur penelitian ini menggunakan model pengembangan ADDIE. ${ }^{7}$ Dalam model pengembangannya juga lebih identik dengan pengembangan sistem pembelajaran. Proses pengembangannya berjalan sistematis dan interaktif, yang berada pada hasil evaluasi setiap tahapan digunakan untuk pengembangan berikutnya. Maksud dari penjelasan tersebut adalah pada hasil akhir dari suatu tahap termasuk produk awal bagi tahap selanjutnya. Ada beberapa karakteristik pengembangan model ADDIE, diantaranya adalah sebagai berikut:

1. Sebuah proses yang terorganisasi dalam pengaplikasian bahanbahan pembelajaran yang telah disediakan pada model perancangan dinamakan dengan model ADDIE

2. Menggunakan pendekatan produk, langkah-langkah yang sistematis dan interaktif

3. Pengembangan bahan pembelajaran pada ranah verbal, ketrampilan intelektual dan psikomotor juga dapat digunakan pada penelitian ini

4. Untuk dapat bekerja sama dengan para ahli isi dan media dengan desain pembelajaran sehingga model ADDIE memberi kesempatan kepada pengembang dan menghasilkan produk yang mempunyai kualitas baik.

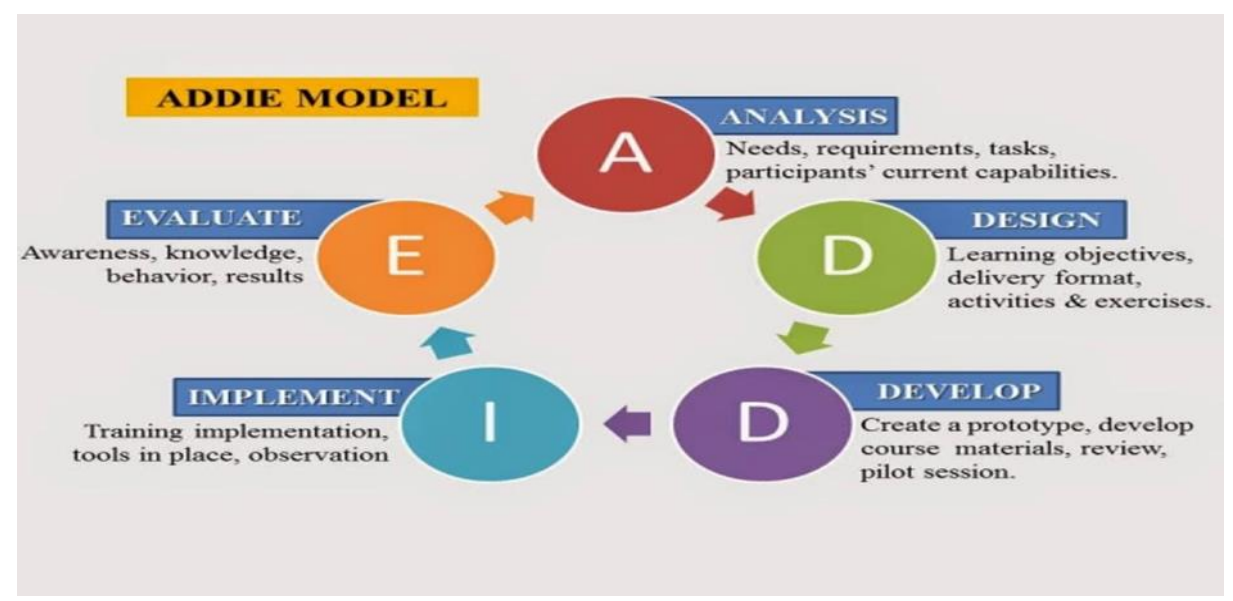

Gambar 1. Bagan Model Pengembangan ADDIE

${ }^{7}$ Amir, Hamzah. (2019). Metode Penelitian dan Pengembangan (Research and Development): Uji Produk Kuantitatif dan Kualitatif Proses dan Hasil. Malang: CV. Literasi Nusantara Abadi, 33. 


\section{HASIL DAN PEMBAHASAN}

Faktor-faktor yang kompleks pada proses pembelajaran berdasarkan hasil riset dengan teori yang telah ditemukan oleh Gagne tentang pembelajaran e-learning yang lebih efektif. Menurut Gagne, untuk mengembangkan proses yang logis maka diperlukan suatu kontribusi dalam belajar terhadap adaptasinya, sehingga perkembangan tingkah laku yang mereka lakukan dapat menjadi hasil dari pembelajaran komulatif. Mekanisme seseorang yang menjadi anggota masyarakat secara kompleks merupakan pengertian belajar yang telah didefinisikan oleh Gagne. Pengetahuan, perilaku, skill dan nilai-nilai karakter tiap individu peserta didik termasuk dalam kompetensi. Hasil pembelajaran dari berbagai macam tingkah laku yang dilakukannya disebut dengan belajar. Dengan demikian, hasil pembelajaran pada proses kognitif, stimulus dan lingkungan tiap individu dapat diperoleh peserta didik berdasarkan kemampuannya.

Cara baru dalam proses belajar-mengajar adalah adanya sistem pembelajaran berbasis web atau bisa dinamakan dengan e-learning. Peserta didik tidak perlu menyimak secara langsung setiap ucapan dari seorang pendidik di dalam kelas. Dapat mempersingkat waktu pembelajaran menggunakan media e-learning karena biasanya harus mendengarkan seksama di kelas. Media pembelajaran e-learning mempunyai empat karakteristik, yaitu dapat memberikan manfaat terkait jasa elektronik, keunggulan komputer, dapat memberikan suatu informasi terkait pembelajaran yang diajarkan pada hari itu dan memanfaatkan komputer untuk dapat menyimpan jadwal pelajaran, halhal yang berkaitan dengan administrasi bahkan hasil pembelajaran yang nantinya akan dikembalikan berupa penilaian dari pendidik. Dalam $e$ learning terdapat kelebihan dan kelemahan yang dimiliki. Adapun penjelasan tentang kelebihan e-learning ada tiga, yaitu dengan menggunakan fasilitas multimedia yang lebih mudah diserap, efektif dalam pembiayaan dan lebih ringkas. Sedangkan kelemahannya adalah tidak semua tempat tersedia fasilitas internet, kurangnya interaksi secara langsung antara pendidik dan peserta didik, dalam proses belajar mengajar lebih mengarahkan pada pelatihan daripada ke dunia pendidikan, kurangnya sumber daya manusia yang dapat menguasai internet dengan baik dan peserta didik akan merasa terisolasi. 
Untuk membuat peserta didik lebih bersemangat lagi belajar dan berinteraksi dengan lingkungan sekitarnya, maka adanya edmodo sangat dibutuhkan oleh peserta didik. Di dalam edmodo, pendidik juga dapat membuka diskusi kelas online yang memberikan pemahaman terhadap peserta didik dengan materi surah az-Zalzalah. Edmodo juga memudahkan pendidik untuk dapat melacak perkembangan kemajuan pada tiap peserta didik. Semua rencana belajar dan penilaian diberikan melalui edmodo. Seorang pendidik mendapat masukan di ruang kelas melalui reaksi atau tanggapan para peserta didik untuk kuis, tugas dan postingan materi diskusi yang menangkap pemahaman peserta didik.

Implementasi Edmodo sebagai peserta didik adalah sebagai berikut:

1. Masuk dalam pendaftaran dan mengisi identitas diri peserta didik yang meliputi nama, username, email dan password atau dapat menggunakan akun google yang telah terdaftar pada handphone.

2. Dengan menyesuaiakan kode yang telah diberikan oleh seorang pendidik, kemudian peserta didik dapat mengisi dan gabung dalam grup kelas tersebut.

3. Setelah berhasil sign up, bisa masuk ke halaman awal pada beranda.

4. Dengan cara memasukkan kode kelasnya, maka peserta didik dapat menambahkan grup kelas yang telah diberikan.

5. Setelah selesai tergabung, maka pada tampilan profile dapat ditambahkan foto masing-masing peserta didik.

Diperlukan validasi dengan baik dari ahli media, untuk mengetahui tingkat kelayakan dalam media pembelajaran yang dapat memperbaiki media pembelajaran sebelum dilakukan ujicoba kepada peserta didik. Validasi ahli materi dan media terdiri dari 3 dosen telah didapatkan pada penelitian ini. Berdasarkan hasil penelitian dan analisis data, pengembangan pembelajaran al-Qur'an Hadits materi surah az-Zalzalah media e-learning melalui edmodo dinyatakan baik dengan hasil rating $78,34 \%$ sehingga dapat digunakan sebagai media pembelajaran di Madrasah. Pengembangan pembelajaran al-Qur'an Hadits materi surah az-Zalzalah media e-learning melalui edmodo dapat pula dikatakan baik dan memperoleh hasil rating keseluruhan $82,36 \%$. Beberapa peserta didik juga mengatakan bahwa dengan adanya media pembelajaran ini, 
maka bisa mengakses materi yang dipelajari dengan mudah melalui jaringan internet edmodo.

Sedangkan tahap pada pengembangan produk yang digunakan oleh model penelitian ADDIE, adalah sebagai berikut:

1. Tahap Analisis, berdasarkan observasi yang telah ditemukan bahwasannya peserta didik tidak asing lagi dalam menggunakan atau mengaplikasikan teknologi informasi. Meskipun terdapat kendala dalam menggunakan edmodo, akan tetapi partisipasi dan usaha yang peserta didik lakukan dapat diberikan apresiasi tersendiri.

2. Tahap Perancangan, yang harus dilakukan pertama kali dalam hal perancangan adalah menentukan materi yang disesuaikan dengan kurikulum terbaru dan melihat kondisi pada peserta didik.

3. Tahap Penyusunan, dalam tahap ini yang dilakukan adalah menyusun dan mengembangkan suatu produk yang telah disesuaikan dengan rancangan serta desain sebelumnya. Media $e$ learning melalui edmodo dirancang dengan menggunakan suatu produk. Pengumpulan dari beberapa materi yang akan disajikan dan diperlukan pada tahap penyusunan ini bisa berupa video dan power point.

4. Tahap Implementasi, untuk mengetahui respon mengenai media $e$ learning melalui edmodo dapat dilakukan dan dikembangkan oleh peserta didik.

5. Tahap Evaluasi, evaluasi sumatif dan formatif merupakan hasil implementasi pada tahap evaluasi yang diperoleh dari penelitian tersebut. Untuk menilai suatu produk pembelajaran yang telah dikembangkan dari penilaian evaluasi validasi ahli dan uji coba kelompok kecil di lapangan dilakukan oleh evaluasi sumatif. Sedangkan untuk mengetahui produk yang harus dikembangkan agar lebih efektif dalam proses pembelajaran dapat dilakukan menggunakan evaluasi formatif. 


\section{KESIMPULAN}

Dapat diambil kesimpulan bahwasannya pembelajaran al-Qur'an Hadits materi surah az-Zalzalah pada media e-learning melalui edmodo dikatakan baik dan dinyatakan memenuhi syarat dengan hasil rating $78,34 \%$. Kemudian dapat dinyatakan baik dengan hasil rating $82,36 \%$ pada media pembelajaran yang telah direspon oleh peserta didik. Keseluruhan aspek e-learning melalui edmodo pada pembelajaran alQur'an Hadits dikategorikan baik dan layak digunakan pada proses pembelajaran. Dapat memenuhi kriteria valid dan efektif pada produk media e-learning melalui edmodo dalam suatu pembelajaran al-Qur'an Hadits. Untuk memotivasi dan memfasilitasi pembelajaran interaktif yang mendukung pada pemahaman peserta didik terhadap materi surah az-Zalzalah dapat menggunakan media e-learning melalui edmodo pada pembelajaran al-Qur'an Hadits baik didalam maupun luar kelas.

\section{DAFTAR PUSTAKA}

Alim, N., Linda, W., Gunawan, F., \& Saad, M. S. M. (2019). The effectiveness of Google classroom as an instructional media: A case of state islamic institute of Kendari, Indonesia. Humanities and Social $\begin{array}{llll}\text { Sciences } & \text { Reviews, } & \text { 240-246. }\end{array}$ https://doi.org/10.18510/hssr.2019.7227

Batita, M. S. R., Wijoyo, S. H., Herlambang, A. D., \& Maurish Sofie Rahmi Batita, Satrio Hadi Wijoyo, A. D. H. (2019). Analisis Perbandingan Blended Learning berbasis Edmodo dan Google Classroom ditinjau dari Motivasi dan Hasil Belajar Siswa. Jurnal Pengembangan Teknologi Informasi Dan Ilmu Komputer, 3(4), 3756-3764. http://jptiik.ub.ac.id

Belina, E. P., \& Batubara, F. R. (2013). Perancangan dan Implementasi Aplikasi E-Learning versi Mobile Berbasis Android. IV, 76-81.

Di, P. C.-, \& Nurulhuda, M. I. (2020). Imam Ja 'far Shodiq dan Husniyatus Salamah Zainiyati 144. 6(2), 144-159.

Fandianta dkk. (2013). Meningkatkan Pengetahuan Mahasiswa Dengan Memberikan Fleksibilitas Belajar Melalui Metode Blended learning. Jurnal Pendidikan Kedokteran Indonesia, 2(2), 1-8. 
Hamid, A., Setyosari, P., Kuswandi, D., \& Ulfa, S. (2019). The implementation of mobile seamless learning strategy in mastering students' concepts for elementary school. Journal for the Education of Gifted Young Scientists, 7(4), 967-982. https://doi.org/10.17478/jegys.622416

Hamzah, Amir. (2019). Metode Penelitian dan Pengembangan (Research and Development): Uji Produk Kuantitatif dan Kualitatif Proses dan Hasil. Malang: CV. Literasi Nusantara Abadi.

Hanum, N. S. (2013). Keefektifan E-Learning sebagai Media Pembelajaran: Studi Evaluasi Model Pembelajaran E-Learning SMK Telkom Sandhy Putra Purwokerto. Jurnal Pendidikan Vokasi, III No.1, 92.

Holland, C., \& Muilenburg, L. (2011). Supporting Student Collaboration: Edmodo in the Classroom. In Society for Information Technology \& Teacher Education International Conference, No. 1, 3232-3236.

Junaidi, J. (2018). Model Pendidikan Multikultural. Al-Insyiroh: Jurnal Studi Keislaman, 2(1), 57-72.

Kongchan, C. (2008). How a non-digital Native Teacher Makes use of Edmodo. ICT.

Media, P., Learning, B., Edmodo, B., Sekolah, D. I., Kejuruan, M., Development, T. H. E., Blended, O. F., Media, L., \& On, B. (2015). Indonesian Journal of Curriculum. 3(1), 16-23.

Mufaizin, M., \& Arafat, Y. (2020). Implementasi Metode Jibril dalam Meningkatkan Kemampuan Membaca Al Qur'an Kelas C2 Tahsin Tilawah Lembaga Takhassusul Qur'an Darul Hikmah. AL-THIQAHJurnal Ilmu Keislaman,3(01), 39-54.Munadi. (2008). Media Pembelajaran (Sebuah pendekatan baru). Gaung Persada Press.

Pendidikan, S., Elektro, T., Surabaya, U. N., Elektro, T., Teknik, F., \& Surabaya, U. N. (2009). PENGEMBANGAN MEDIA PEMBELAJARAN E-LEARNING MENGGUNAKAN EDMODO PADA MATA PELAJARAN ELEKTRONIKA DASAR STUDI PADA SISWA KELAS X TEI SMK NEGERI 2 BOJONEGORO Wisda Putra Atmanegara Puput Wanarti Rusimamto Abstrak.

Penelitian, A., Universitas, P., \& Madiun, P. (2018). Jurnal Bidang Pendidikan Dasar (JBPD), Vol. 2 No. 1 Januari 2018 http:ejournal.unikama.ac.id/index.php/JBPD. 2(1), 63-68. 
Program, J., \& Pendidikan, S. (2020). PENGEMBANGAN MEDIA ELEARNING BERBASIS EDMODO PADA Universitas Sembilanbelas November Kolaka , Kolaka , Indonesia E-mail: Abstrak PENDAHULUAN Perkembangan teknologi informasi dan komunikasi di era revolusi industri 4 . 0 telah mempengaruhi semua aspek Pe.9(4), 872-882.

Ramdhan, T. W. (2019). Model Pengembangan Kurikulum Multikultural. AlInsyiroh: Jurnal Studi Keislaman, 5(2), 39-53.

Rusman. (2014). Pendekatan, Strategi, dan Model Pembelajaran. PT Raja Grafindo.

Samudra, U. (2018). Improving Character Education Strengthening Through. Setiawan 2013, 2262-2267.

Smp, D. I., Depok, M., Dahlan, U. A., Dahlan, U. A., \& Dahlan, U. A. (2016). PENGEMBANGAN MEDIA E-LEARNING BERBASIS EDMODO PADA MATA PELAJARAN MATEMATIKA KELAS VII. 84-87.

Sugiyono. (2017). Metode Penelitian Kuantitatif, Kualitatif dan R\&D. Alfabeta.

Wirawan, P. W. (2011). Pengembangan Kemampuan E-Learning Berbasis Web Ke Dalam M-Learning. Jurnal Masyarakat Informatika, II No. 4, 22-23. 